\title{
INTENSIONAL TRANSITIVES AND PRESUPPOSITIONS
}

\author{
R.M. SAINSBURY \\ Department of Philosophy \\ University of Texas at Austin \\ marksainsbury@mail.utexas.edu
}

SUMMARY: My commentators point to respects in which the picture provided in Reference without Referents is incomplete. The picture provided no account of how sentences constructed from intensional verbs (like "John thought about Pegasus") can be true when one of the referring expressions fails to refer. And it gave an incomplete, and possibly misleading, account of how to understand certain serious uses of fictional names, as in "Anna Karenina is more intelligent than Emma Bovary" and "Anna Karenina does not exist". In the present response, I indicate how I would now wish to make good these deficiencies. The truth of sentences constructed from intensional verbs can be explained in terms of the truth of sentences that are unproblematic for $R W R$, for example, sentences dominated by operators expressing propositional attitudes. Reflection on the way in which we can temporarily accept commitments we do not in fact share leads to a more nuanced account of serious uses of fictional names, some of which manifest precisely such a temporary acceptance.

KEY WORDS: reference, empty names, fiction, intensionaliy

RESUMEN: Mis comentadores señalan aspectos en los que la propuesta de Reference without Referents es incompleta: no ofrecía una explicación de cómo oraciones construidas con verbos intensionales (como "Juan pensó en Pegaso") pueden ser verdaderas cuando una de las expresiones referenciales no refiere; y dio una explicación incompleta, y quizás engañosa, de cómo entender ciertos usos serios de nombres de ficción como en "Anna Karenina es más inteligente que Emma Bovary" y "Anna Karenina no existe". En esta respuesta indico cómo quiero ahora subsanar estas deficiencias. La verdad de las oraciones construidas con verbos intensionales puede explicarse en términos de la verdad de oraciones que no son problemáticas para la explicación de Reference without Referents, por ejemplo, oraciones dominadas por operadores que expresan actitudes proposicionales. Una reflexión sobre cómo podemos aceptar temporalmente compromisos que de hecho no compartimos conduce a una explicación más matizada de los usos serios de los nombres de ficción, algunos de los cuales manifiestan precisamente esa aceptación temporal.

PALABRAS CLAVE: referencia, nombres vacíos, ficción, intensionalidad

It is a pleasure to have received such penetrating responses, and also to see that none of the respondents shows any inclination to return to the sterile oscillation between Millianism and descriptivism, which it was the main aim of the book to deconstruct. The comments raise a number of difficult questions, and I'm happy to have this opportunity to try to address them afresh. The overall structure of the responses is by theme, with the individual respondents discussed within the relevant themes. 


\section{Homophony and Context}

Manuel García-Carpintero asks why I say that homophony is an ideal: "If it is false that homophonic theories account for our language mastery, how can this falsehood nonetheless constitute any ideal?" (p. 00). I'm not sure that I accept the implied principle (presumably the things textbooks say about ideal gases are strictly speaking false), but I admit that my talk of homophony as an ideal was not happy. The main point I wanted to make was this: were it not for the contextsensitivity of language, all semantic specifications could properly be homophonic. To accept this point is to accept that one good project in semantics, in which object language and metalanguage coincide, consists in something other than what I called reduction: specifying meanings in other terms. A homophonic specification carries with it a guarantee of correctness. There is no analogous straightforward way to check that non-homophonic specifications are correct, and we can be sure that at least some are incorrect, since some words, like "red", have meanings that cannot be specified in other terms.

I did not wish to suggest that context-sensitivity would be absent from an ideal language. On the contrary, I find it impossible to envisage a language, usable for anything like the purposes to which natural languages are adapted, that could fail to be deeply sensitive to context. So I would regard it as folly to suggest that theorists should treat homophony as an ideal in the sense of something to which they should aspire in their treatment of natural language. On the contrary, I devoted some space to seeing how non-homophonic conditional truth-conditions should be constructed, and I agree with García-Carpintero that this is the best (and so in some sense ideal) approach to at least some kinds of context sensitivity. I also agree with him that the approach should probably be extended to proper names. Not doing so in the book was intended as a genuine case of "idealization": ignoring awkward details in order to simplify the presentation of the main elements of the proposal.

Or so I thought at the time. Since then, and spurred on by more than one of the present commentators, I now wonder whether that view is justified. It may be that, as García-Carpintero suggests here and elsewhere, a semantics of proper names should be developed using some notion of presupposition, in a way that will throw light on the use of proper names in fiction and similar contexts. I'll consider that idea towards the end of this reply. 


\section{Intensional Transitives}

Tim Crane is unpersuaded by the book's claim that it's false that Le Verrier thought about Vulcan. Here we enter tricky territory: it's hard to form stable judgments about the truth value of such sentences, especially when they are offered with no surrounding context. There are deep and moderately systematic reasons for this, as I hope to bring out below.

I don't find it crazy to suppose that it's false that Le Verrier thought about Vulcan. The truth, consistent with RWR, is that it seemed to him that that was what he was doing, and we may helpfully adopt his perspective for some purposes. Adopting it, and so presupposing that there's such a thing as Vulcan, then of course Le Verrier did think about Vulcan. But I have to agree with the thrust of Crane's point: there are cases concerning which it would not be open to me to take this line. An example is:

1. "Vulcan" purports to refer to Vulcan.

This is a central claim of the book, and not one I'm willing to give up or qualify. So I accept Crane's criticism: I need to provide a different account of at least some examples of this general kind.

Suppose that I were to make a small modification to one basic claim of RWR. Instead of saying that the occurrence of an empty name in a simple sentence ensures that the sentence is false, perhaps I should say that the occurrence of an empty name in a simple extensional sentence ensures that the sentence is false. If it is granted, as it normally would be, that both "thinks about" and "purports to refer to" are in some sense non-extensional, it seems that I can then allow for the truth both of (1) and of "Le Verrier thought about Vulcan".

As far as I can see, it would not be incorrect to do this; but it would create a disagreeable mystery, as I think Crane agrees. In the case of at least some non-extensional sentence operators, like "John believes that", we can explain how it is that they can form truths from sentences that, under the RWR rule for the behavior of empty names, come out false. The explanation is that the operators need only to find a content in the sentence they embed. There is, as Crane stresses, no general rule to calculate the truth value of the whole sentence on this basis, but sometimes an embedded false content will lead to a truth overall, as in "Bush believes he never makes mistakes". If we merely say that intensional transitive verbs, 
like "thinks about", don't require reference for truth, we leave it mysterious how this can be so.

Unless, that is, we can somehow explain the truth of sentences built from intensional transitives in terms of sentences built from non-extensional sentence operators. We might, for example, explain the truth of (1) in terms of the truth of

2. It is purported that "Vulcan" refers to Vulcan.

Since, according to RWR, the embedded sentence in (2), though false, has a genuine content, the truth of (2) poses no problem for the theory. So if we can explain the truth of (1) in terms of (2), we can, after all, explain how the use of "Vulcan" in (1) doesn't need to have a referent for (1) to be true.

This sounds pretty much like the approach Crane calls "the reduction of intensional transitives" and which he argues is misguided. However, there is a significant difference. Where I speak of explaining the truth of $\mathrm{x}$ in terms of the truth of $\mathrm{y}$, Crane speaks of analyzing $\mathrm{x}$ in terms of $\mathrm{y}$ (others speak of $\mathrm{y}$ being the logical form or paraphrase of $\mathrm{x}$ ). He attacks the view that "all reports of intentional states can be analyzed as propositional attitude reports". But whereas the relation of analysis is normally taken to require necessary equivalence, one might properly explain the truth of $x$ in terms of the truth of $y$ without $x$ and $y$ being equivalent. For example, in a given situation the truth of "Something is barking" might be explained in terms of the truth of "Fido is barking". This relation is much weaker than that of analysis. So let's call "reduction*" the thesis that we can explain the truth of sentences built from intensional transitives (call these "IT-sentences") in terms of the truth of sentences in which the only intensionality is introduced by non-extensional sentence operators (call these "SO-sentences"). We confront two questions:

(1) is reduction* subject to the criticisms Crane offers of the reduction of intensional transitives?

(2) Would the truth of reduction* suffice to salvage RWR, along with our intuitive judgments of truth value?

One criticism Crane makes is that the IT-sentence "Vladimir will look for a bottle of burgundy tomorrow" cannot mean the same as the SO-sentence "Vladimir will look to find a bottle of burgundy tomorrow". That's because the SO-sentence is ambiguous whereas the IT-sentence is not. One reading of the SO-sentence has Vladimir 
starting his search today (knowing it will take all of 24 hours to bring it to a successful conclusion) whereas the IT-sentence requires him to start looking tomorrow. I'm not certain I share these judgments, but for those who do, there's an easy remedy: as SO-sentence, use "Tomorrow, Vladimir will look to find a bottle of burgundy". As far as I can tell, this has only the appropriate reading.

Crane's central criticism concerns thinking about, and I agree with him that this is an absolutely crucial case. If reduction* holds here, I would be fairly confident that it would hold across the board. But Crane says that reduction* (or at any rate reduction) does not hold. He offers two reasons. The first relates (in effect) to this sentence:

3. TC imagines (and so thinks about) winning the lottery.

Crane agrees that for this to be true, TC must have some beliefs about the lottery. "But this is just a necessary condition for imagining; the beliefs do not constitute imagining it" (p. 93). It may be that if $x$ can be analyzed as $y$, the truth of $x$ is "constituted by" the truth of $y$. The same does not hold for my preferred relation, explaining the truth of $x$ in terms of the truth of $y$. This enables me to offer, as explanations, different sufficient conditions in different cases. In one case, I explain the truth of (3) in terms of TC imagining that he has won, in another in terms of TC appreciating that he has probably lost ("Winning the lottery will never happen to me"). I do not say that any one SO-sentence will provide an explanation across the board; only that, for every IT-truth, there is an SO-sentence in terms of whose truth the truth of the IT-sentence can be explained.

Crane also offers a more general reason for suspecting that there's no reduction of "thinking about":

whenever someone thinks about $X$, they have to be thinking about it in some way. That is, they might be imagining $X$, visualising $X$, speculating about $X$, contemplating $X$, judging something about $X$, fearing $X$, hoping for $X$ and so on. And for only a few of these is a propositionalist reduction available.

Even if there are cases in which there is no reduction to SO-sentences, it might be that in every case there is a reduction*. To take just one example: in one case we might explain the truth of fearing $\mathrm{X}$ in terms of the truth of believing that $\mathrm{X}$ is dangerous; in another, in terms of the truth of finding that being in the presence of $\mathrm{X}$ makes one very uneasy. 
I don't deny that there is unfinished business; these remarks only hint at a project. But rather than pursue it now, I'll turn to the second question: what is the relevance of these reductions* to our original problem? The problem was whether we could explain how an IT-sentence could be true if a name (or other referring expression) in it lacked a referent. This problem should now not look at all hard. If we can explain how an SO-sentence containing an embedded empty name can be true despite this lack, and if the truth of such sentences explains the truth of the target IT-sentence, which is what reduction* claims, we've surely explained how the IT-sentence can be true despite having a name with no referent. ${ }^{1}$ Admittedly, we have not given anything that looks like a semantic theory for IT-sentences (nor a reduction, analysis, paraphrase or logical form proposal); but if we wish merely to know whether RWR is scuppered by IT-sentences, we have no need of these more ambitious aims.

Here's an example of the detail that explanatory chains from SOtruths to IT-truths can offer. They can account for the fact that some truths built from intentional transitives seem to be object-involving in a way that others do not. In the way that "Tony Blair admires George Bush" is in fact true, there needs to be a George Bush. In the way that "Tony Blair admires Sherlock Holmes" is (we'll suppose) in fact true, there need be no Sherlock Holmes. The contrast is explained by the nature of the underlying SO-truths. In the first case, these truths will embed a sentence with a rigidly referring name "George Bush" that has a referent; hence the explaining state of affairs will be one containing George Bush. This is not so in the other case, in which, in the relevant SO-sentences, "Sherlock Holmes" has no referent.

Although I am not persuaded by Crane's criticisms, I am in favor of his positive proposal:

$\mathrm{S}$ thinks about $X=_{d f} \mathrm{~S}$ is in some conscious state of mind which represents $X$.

I would like to add: being in a conscious state which represents $X$ is having some propositional attitude to a content that can be expressed in a sentence part of which purports to refer to $X$. "Purporting to refer to" I have already shown to be innocuous from the point of view

\footnotetext{
${ }^{1}$ This can be so even if not so in virtue of a formal principle, say transitivity. Perhaps the following principle, weaker than transitivity, is without counterexample and strong enough for the present case: if $x$ can be used to explain $y$ and $y$ can be used to explain $z$, then $x$ and $y$ together can be used to explain $z$.
} 
of RWR. Putting these points together might enable me to elevate my reduction* to a reduction.

\section{Negative Existential Truths}

Simple sentences like "Vulcan exists" are false, according to the negative free logic which RWR embraces, and so their negations are true. Mircea Dumitru and Frederick Kroon argue that this does not get to the bottom of the problem of negative existential truths. I now agree with them, though not entirely for their reasons.

They present an argument by dilemma. Take the following to be true (I use their numbering):

5. Vulcan - you know, the planet described in that interesting paper by Le Verrier that we have been reading- does not exist.

They offer two readings:

6. Vulcan is the planet described in that interesting paper by Le Verrier that we have been reading, and it [Vulcan] does not exist.

7. The thing $x$ such that $(x=$ Vulcan and $x$ is the planet described in that interesting paper by Le Verrier that we have been reading) does not exist.

Dumitru and Kroon say that although (7) is true, it cannot be what is intended by (5), for it makes the material about Le Verrier's interesting paper irrelevant. By the lights of RWR, no matter what $p$ is, "The $x$ such that $(x=$ Vulcan and $p)$ does not exist" is true (negation taking wide scope), which does not do justice to (5)'s dependence for its truth on the existence of the interesting paper by Le Verrier. And (6), they say, is false. I disagree. I think that " $x$ describes $y$ " is an intensional transitive, and so, accordingly, is " $y$ is described by $x "$. Everyone agrees that a sentence built from this verb can be true when the occupant of the $y$ position lacks a referent; and if the earlier claims about reduction* is correct, this fact is not troubling to RWR.

Even so, I think Dumitru and Kroon are right to say that there is something lacking in the RWR account of existential sentences, and I think they put their finger on it when they bring it under the broader heading of cases in which "we speculatively engage with 
the commitments of those whose commitments we don't share". Even if RWR got the truth conditions right, it did not do justice to this feature. I agree with Dumitru and Kroon that this activity is important, ${ }^{2}$ and it helps us to understand some of the puzzles about fictional names, as I'll argue in the coming section.

\section{Fiction}

Eleonora Orlando claims that, in the book, I say that

S. Holmes is a detective

"should be understood in terms of"

$\mathrm{S}^{\prime}$. According to the fiction, Holmes is a detective.

That was not my view in the book (rather, I said that one might explain the "somewhat uncertain" intuition that $(\mathrm{S})$ is true if it was treated as $\left(\mathrm{S}^{\prime}\right)$ ) and I would now repudiate it more firmly. One might understand $(\mathrm{S})$ without understanding $\left(\mathrm{S}^{\prime}\right)$, or even having any grasp of what fiction is, so $\left(\mathrm{S}^{\prime}\right)$ cannot give the meaning of $(\mathrm{S})$, and nor is it what speakers typically mean by uttering $(\mathrm{S})$. As Orlando says, the most typical uses of $(\mathrm{S})$ are in telling or retelling the fiction.

There are residual problems in this area which I admitted in the book that I could not resolve to my entire satisfaction. Two such, using Orlando's labels, are:

K. Anna Karenina is more intelligent than Emma Bovary.

I. Tony Blair admires Coriolanus.

(I) is built round an intensional transitive, so if the earlier remarks in this paper are correct, it need cause no alarm to an RWR theorist. ${ }^{3}$ But $(K)$ is not so constructed, and so requires a different account.

An approach in keeping with the way I was thinking when I wrote the book would be to treat it just like $(\mathrm{S})$ : $(\mathrm{K})$ is strictly and literally false. However, we can extend the notion of fidelity so as to

${ }^{2}$ However, I see no need for it in one of the cases they address:

Hallucinating a little green man in the corner of the garden, she pointed at him, and said that he was bald.

The authors say that this is intuitively true, which it is not according to RWR. I'll simply report that I don't think one can really point to hallucinatory objects, for there are no such things.

${ }^{3}$ In the book, I assumed that Coriolanus was a purely fictional character, which he was not. 
amalgamate more than one source, as we do when we contemplate testimony from several witnesses. Then if we wish to find a truth in the neighborhood (emphatically not a "paraphrase") it's something like: according to the novels taken together, K. Alternatively, we can think of the ascription of truth to $K$ as really the description of fidelity, though now fidelity to an amalgam of two novels.

Although I don't think this is incorrect, it's no longer my preferred approach. Rather, in keeping with Dumitru and Kroon's suggestion, I think we should explore the way in which we can provisionally adopt the commitments of others, without ourselves committing to them. One conspicuous area is anthropology, or cultural studies more generally. An outsider can report as from within the culture or cultures. People who do not believe in gods or ghosts could firmly believe that the Christian god is benevolent, unlike some of the Hindu deities, and that ghosts change over time, reflecting changing shared anxieties in the relevant culture. In these cases we have presupposition-relative truth and belief. Contexts can force one to step back, abandoning the presuppositions: there are no gods or ghosts, so I was really telling you about the beliefs in those cultures, not about my own beliefs. And contexts can appropriately or even inevitably make one step forward, entering into presuppositions that one does not believe. Even if you are a little skeptical about the professed illness, there may now be no better way to put the question than "How's the headache?" I can accept as a presupposition that my interlocutor has a headache, even if I do not believe this.

Entering into the perspective of another is an essential part of communication. If I tell you I'm spending Thanksgiving with my sister, you typically end up knowing that I have a sister, even if you did not know it before. This makes available to you a new referring device, "his sister". Adopting my perspective, there's a sister to refer to. In an untypical case, I am deceiving you: I have no sister and I am spending Thanksgiving on my own. My remark still makes the referring device available to you, though this time it has no referent. You adopt what you take to be my perspective, perhaps wondering whether my sister is older or younger. When you are undeceived, you can think: he has no sister, or there's no such person as his sister. In this case, you need, in David Wiggins's words, to have a foot in each of two perspectives: what you took to be mine, which makes available the referring device, and that of the real world, which reveals it as empty.

Fluctuations of perspective make for some instability in judgments of truth. Someone affirms that Holmes lived in Dover Street. "No", 
you say, in full sincerity, "He lived in Baker Street". Your assertion is sincere; that is, you take what you asserted to be true. So don't we have evidence for the view (which seems apparent to Orlando) that the sentence "Holmes lived in Baker Street" is true? It's more complicated. The original affirmation set the context to fiction, indeed to a specific fiction (the Holmes stories). Your sincerity consists in saying what you take the fiction to say. But you can be snapped out of this context. The conversation turns to electoral rolls, registry records, and so on. Then it will seem absurd to suggest that the records for Marylebone in the 1880s are incomplete, merely on the grounds that no Sherlock Holmes is recorded in Baker Street. From this perspective, "Holmes lived in Baker Street" will strike you as obviously untrue, and as unavailable for use in sincere assertion.

This explains why intuitions about truth values can be unstable: they are dependent upon context. This effect is not confined to fiction. As García-Carpintero stresses, we need something similar to explain non-fictional uses. How is it that when you use "Aristotle" in speaking to me, I know you're talking about the philosopher, not the shipping magnate? You are the local ancient philosopher; that's normally a good clue. What you said was that Aristotle wrote the Nicomachean Ethics; that settles it. I make a presupposition about which Aristotle you're referring to, and my evaluation of your remark is relative to this. Presuppositions are also at work in cases central to Frege's puzzle. We can't guarantee that all instances of " $x=$ $x "$ are true, even when the replacements for " $x$ " have referents. A contextual shift may occur between first and second occurrence. If I treat "Hesperus is Hesperus" as trivial or uninformative, it's because I presuppose "Hesperus" is being used in the same way in each of its occurrences. Paderewski cases show that we can concoct informative instances of " $x=x$ ". The explanation is precisely that someone for whom the instance is informative does not presuppose that "Paderewski" is being used in the same way in each of its occurrences.

In this response, I've gestured at two theses which I think would help complete RWR and would address problems my commentators have raised. (1) In order to deal with empty referring expressions as they occur in IT-sentences, I need to be able to explain these truths in terms of RWR-friendly truths, notably SO-truths. (2) In order to give an adequate account of serious uses of empty referring expressions in ordinary extensional sentences, I need to appeal to some notion of presupposition, and presupposition-relative truth. Here I have merely gestured at the two theses, but I believe that they can be developed 
in proper detail, and that they help complete the picture offered by RWR. ${ }^{4}$

\section{REFERENCES}

Jeshion, R. (ed.), 2009, New Essays on Singular Thought, Oxford University Press, Oxford.

Sainsbury, R.M., 2009a, "Intentionality without Exotica" in Jeshion 2009. , 2009b, Fiction and Fictionalism, Routledge, London.

— 2005, Reference without Referents, Clarendon Press, Oxford.

Received: January 5, 2009; accepted: January 12, 2009.

${ }^{4}$ I've attempted to develop these ideas further in Sainsbury 2009a, "Intentionality without Exotica", and Sainsbury 2009b. 